\title{
Developing a Poverty-Aware Pedagogy: From paradigm to reflexive practice in post- academic social work education
}

Griet Roets, Laura Van Beveren, Yuval Saar-Heiman, Heidi Degerickx, Caroline Vandekinderen, Michal Krumer-Nevo, Kris Rutten \& Rudi Roose

\begin{abstract}
Social work scholars have argued that poverty reminds us of the necessary commitment to educate professional social workers in the development of poverty-aware practices. Being inspired by a conceptual framework that captures how poverty-awareness can be the subject of teaching in social work programs, this article offers a qualitative analysis of the reflections being made by a cohort of students about their learning process in a post-academic course. Five common themes are discussed: (1) from recognizing micro-aggressions to tackling macroaggressions, (2) poverty is an instance of social injustice and requires collective indignation, (3) notions of commitment and solidarity are ambiguous, (4) poverty is an instance of social inequality rather than merely social exclusion, and (5) from being heroic agents to social change 'from within'. Based on these findings, we raise the lessons learned for social work educators.
\end{abstract}




\section{Introduction}

In the international realm, social work receives due recognition of policy makers for its vital role as an academic discipline and practice-based profession in the struggle against poverty and social inequality (Garrett, 2002). Social work has a long history in its commitment to deal with this social issue (Villadsen, 2007). However, recent research shows that new forms of social policies became less capable in reducing poverty over the past few decades and might even reinforce social inequalities (Cantillon, 2016; Cantillon \& Van Lancker 2013; Garrett, 2018; Ridge \& Wright, 2011; Wilkinson \& Pickett, 2009). Although a consensus that poverty entails a violation of human rights has been established in the global realm (see Dean, 2015; Lister, 2004), critical social work scholars have raised the pertinent argument that poverty reminds us of the necessary and continuous commitment of social work to reclaim, enhance and pursue political questions of social justice (Lorenz, 2016; Ridge \& Wright, 2011). In that vein, the International Federation of Social Work (IFSW) has recently re-emphasised the profession's social justice value orientation by issuing a renewed global definition of social work (IFSW, 2014). More in particular, the IFSW (2012) has reinforced its commitment to the eradication of poverty: 'In practice all over the world, social workers' concern about poverty has increased because of their long history in working with the marginalized, or excluded, those lacking resources, scenarios which push them to poverty situations" (see Boone et al. 2018, p. 2).

The concept of poverty, nonetheless, is not a neutral but rather a normative, ideological and contested construct, differing according to the ways in which it is defined and constructed by different actors in different societies (Dean, 2015; Lister, 2004). As Lister (2004, p. 12) indicates, "how we define poverty is critical to political, policy and academic debates; it is bound up with explanations and has implications for solutions". The ways in which poverty and anti-poverty policy-making are defined and pursued are influenced by prevailing welfare state regimes in which notions of anti-poverty policy-making largely depend on their respective 
historical as well as contemporary social, political and ideological contexts and motives (Authors; Veit-Wilson, 2000). Hence, in line with the variety of changing social, economic and political policies and concerns prevailing at different times in history and contemporary welfare arrangements, the face of poverty has changed, as well as the measures and strategies to fight it in social work (Author's own, 2018). Therefore, conceptualizations of poverty and antipoverty policy-making in social work may vary in radical ways (Author's own, 2016).

This complexity therefore calls upon social work practitioners to make sense of poverty in wellconsidered and contextualised ways, and challenges them to take a critical and reflexive stance in the social work practices they develop (Davis \& Wainwright, 2005; Garrett, 2002). This makes the question how to educate professional social workers in the development of povertyaware practices extremely pertinent. According to Author's own (2009), there have been numerous attempts to place particular emphasis on the issue of poverty within the framework of social work programs in a diversity of countries. Yet despite these efforts, Author's own argue that "existing social work education programs address problems of poverty (...) in an extraordinarily superficial manner". In their contribution, they therefore propose a conceptual framework that intends to capture how poverty-awareness can be the subject of teaching in social work programs, and express "the hope that adaptations of this framework will be of value for education seeking to develop and strengthen the teaching of poverty" within social work curricula (Author's own).

Being inspired by this framework for social work education that might serve the development of poverty-aware social work practices, we engaged in a pedagogical experiment in a social work education course in Flanders (the Dutch speaking part of Belgium). The course is conceived as a post-academic course for social work professionals who are already fully 
involved in social work practice and want to strengthen their professional perspectives and attitudes in dealing with poverty by enriching their theoretical grounding. This article concentrates on an explanation of how the course is conceived, and offers a qualitative analysis of the reflections being made by a cohort of students in the course about their learning process.

In what follows, we first explain the core features of the conceptual framework for a povertyaware pedagogy, and frame how our course is making sense of these principles. Second, we discuss our research methodology. Third, we discuss our qualitative analysis of the empirical research findings, based on an extensive exploration of the reflections of the students involved in the post-academic course about their learning process. Finally, we raise some lessons learned for social work educators.

\section{Revisiting a conceptual framework for the development of a poverty-aware pedagogy}

The framework of poverty-aware pedagogy contains four interrelated key aspects (Author's own, 2009). To build upon this conceptual framework and to do justice to the course we offered, we will represent a summary of those core principles and explain how we interpret and teach them in our course.

\section{The acquisition of theoretical knowledge}

According to Author's own (2009) the proposed social work training program should provide practitioners with useful practical guidelines about how to deal with poverty, based on robust theoretical grounds. Students should possess "theoretical and empirical knowledge about poverty - its causes; expressions in everyday life; its effects and consequences; the experiences entailed in poverty; the ways to extricate oneself from poverty; and the combating of poverty on both the policy level and the individual, family, and community levels" (Author's own, 
2009). The recommended theoretical knowledge includes current poverty theories and approaches deriving from a variety of disciplines; social and economic policy regarding poverty, including its history, alternative ideologies and normative value orientations; and theoretical knowledge regarding the manifestations of poverty and of social policy on the everyday lives of people in poverty. Students should also gain a critical standpoint regarding poverty theories, and learn about the differences between conservative individual-based explanations of poverty, structural and critical poverty-aware approaches.

In our course, two lessons cover the theoretical backbone of the course, whereas the other lessons deal with the other aspects of the conceptual framework of poverty-aware pedagogy. A first lesson departs from social policy theory, and explains how poverty can be defined as a social and multi-dimensional problem that relates to the (re-)production of social inequalities in our societies (Cantillon, 2016; Ridge \& Wright, 2008). In addition, the potential Matthew effects (accumulated advantage in terms of the rich who get richer and the poor who get poorer, see Rigney, 2010) that emerge in redistribution policies are described and explained. The lesson also concentrates on the question how to measure poverty, defined as a lack of material as well as immaterial resources, and argues for strategies of structural redistribution of resources and power as a relevant anti-poverty strategy. A distinction is made between structural (based on a redistribution of resources to prevent poverty) and remedial (based on alleviating the consequences of poverty) anti-poverty policies and practices, and both strategies are illustrated and related to contemporary social policies and social work practices. The cliffhanger of this lesson entails the argument that remedial anti-poverty strategies, which are often shaped by social work, can be framed as nothing more than 'symptom treatment' of the root causes of the poverty problem if they are not interrelated with structural anti-poverty strategies, and therefore - in that case - are neither effective or meaningful (see also Boone et al., 2018). 
In the second lesson, social work is however explicitly situated and reclaimed as an applied policy actor in society (Weiss-Gal \& Gal, 2014; Marston \& McDonald, 2014 ), that has a vital role to play in the development of both structural as well as remedial anti-poverty strategies. Furthermore, the normative value orientation of social work in the promotion of social justice and human rights in relation to situations and instances of poverty and social inequality is explained, with reference to the Global Definition of Social Work (IFSW, 2014). Poverty is accordingly defined as a violation of human rights (see Dean, 2015; Lister, 2004). In that vein, social work is framed as a practice-based profession that has a long-term commitment in the struggle against poverty and accordingly seeks to substantially realize citizenship and welfare rights in its search for social justice (Lorenz, 2016). The lesson also elaborates on a historical contextualization of how the normative value orientation of social work emerged during the last centuries, with reference points at the end of the $19^{\text {th }}$ century, the post-secondworld-war period, and contemporary developments. Continuities as well as discontinuities are discussed, more specifically in relation to the underlying assumptions of charity-based and rights-oriented social work approaches and the emergence of neo-philanthropy (Morvaridi, 2016; Villadsen, 2007). These reflections on social work's historical position within varying political contexts are used to promote a critical examination of the profession's political role and highlight the necessity to develop poverty-aware rather than poverty-blind practices in an attempt to ensure human rights, equality and solidarity in our societies (see Lorenz, 2016).

\section{The development of self-reflection to avoid othering}

The second aspect of a poverty-aware pedagogy is the development of the abilities of students to recognize their personal cultural values, attitudes and ideologies relating to people in poverty through a process of self-reflection. Public standpoints towards poverty and their connection to policy, oppression, and discrimination often reflect stereotypes and prejudices. Entering in this 
critical awareness and self-reflection, is necessary to avoid othering, i.e. to avoid a stereotypical perception of people in poverty as having certain traits and behaviors that are dramatically different from that of other members in society. Othering involves a concrete and symbolic gap between those living in poverty, choosing the 'immoral path', and the powerful majority, choosing the so-called 'moral path'. This relational process also leads to micro-aggressions, consisting of subtle, apparently innocuous behaviors that lead to experiences of shame and humiliation of people in poverty, engaged in by both the general public and professionals in their interactions with poor people (Author's own, 2009).

In the course, we explain to our students that the objective of the course entails an attempt to teach them the necessary grammar - in terms of theoretical and practical frameworks - that allows them to develop a critical yet pragmatic reflexivity in approaching instances of poverty. Here, we explicitly frame a role for social work in shaping the relationship between the individual and society rather than remediating and empowering the individual (see Lorenz, 2008). In that vein, a critical awareness and consideration of the impossibility for individual social workers to 'solve' the complex social problem of poverty is vital during the course (see Authors). We urge them to think about poverty as a structural problem of major social inequalities that persistently disfigures and constrains the lives of citizens (Lister, 2004). We invite them to engage in the discussion on how social work can radicalize and realize its social justice aspirations and challenge structural and systemic forces while accepting that social work is always intrinsically involved in working in remedial ways with individuals; families, and groups (Boone et al., 2018; Lorenz, 2008).

Moreover, students need to learn to position themselves in relation to discourses and practices in their own organizations and in society. We explicitly rely on the work of the social pedagogue Freire (1970) who enables us to pay particular attention to the development of a critical praxis. In his viewpoint, both people in poverty ('the oppressed') and the non-poor ('the 
oppressors') are trained to think and act within the boundaries of realities being perceived as evident and unchangeable, and have adopted a 'culture of silence'. In that sense, they both produce and reproduce a praxis that reaffirms processes of Othering in terms of 'us' and 'them' (Freire, 1970). During the course, we repeatedly discuss and enable the students to identify mindsets that are nowadays re-emerging, especially when a binary and pre-welfare state distinction between 'good' and deserving versus 'bad' and undeserving citizens is at stake (see Villadsen, 2007).

Furthermore, we actively stimulate both individual as well as collective moments of reflection. We rely on Freire's notion of cultural action for freedom, as "the action and reflection of men and women upon their world in order to transform it" (1970, p. 52). Essential to this process is the development of a critical consciousness of the contradictions and elements in all of our lives as oppressed and oppressors, as well as an understanding of the structures of oppression (Larson \& Allen, 2006). In that vein, we enable the students to develop pertinent arguments and create "cultural forums for public debate, in which the power relationships and underlying framework of the social order can be challenged and changed in transformative ways" (Boone et al., 2018, p. 3).

\section{The acquisition of practical knowledge}

Author's own (2009) have asserted that students need to become acquainted with a diversity of poverty-aware practices with people in poverty, their basic assumptions and rationales, the working principles and values they hold, and the specific strategies they use. Since practice with people living in poverty is rich and dynamic, they consider it particularly important that students become acquainted with different practices within the professional realm of governmental or municipal social services as well as outside the established social work field, 
for example, within civil society organizations. In this context students will learn to critically access the welfare services organizational system.

In the course we offer in Ghent, six lessons are dedicated to discussions of the way poverty-aware principles and practices are developed in a diversity of fields of practice, in which public services are often confronted with issues and problems of poverty. We invite guest speakers who teach about early childhood education and care, child welfare and protection, education, health care, public welfare services, and community development and socio-cultural work practices. In each of the lessons, we invite a researcher who has developed a considerable interest and research in that particular field, and practitioners who relate to the research findings and tell the students about the complexities in their attempts to avoid poverty-blind approaches and to develop poverty-aware practices with their colleagues and organizations. The invited guest speakers were selected on the basis of their explicit commitment to discuss not only issues of social exclusion towards people in poverty (see Lister, 2004), but also dynamics in which social inequalities are produced and reproduced in these fields of research, policy and practice. Putting poverty in the context of inequality that requires politics of redistribution of resources and power (Lister, 2004; Ridge \& Wright, 2011) is desirable in order to have a full povertyaware approach. This is especially important in light of the predominant poverty discourse in Belgium that focuses on social exclusion (see Vranken, 2007), and on policies enhancing empowerment (De Pauw \& Driessens, 2016; Van Regenmortel, 2002), that dismisses the structurally needed changes (see Garrett, 2018).

In each of the lessons, we reflect on the question what a rights-oriented approach might mean in research, policy and practice, and try to open up discussions about the organizational climate in which our students are enmeshed and the ways in which social workers can position themselves in their environments. 


\section{Acquiring practical experience of people in poverty}

Author's own (2009) assert that students need to experience working with, or on behalf of, people in poverty on different levels, including the integration of the micro-, meso-, and macrolevel. These experiences are meant to adopt the principles of partnership and reciprocity. According to this perspective, social workers are allies of people in poverty, and reject exclusive expertise as the ones who know better than those living in poverty. From that position, students are required to integrate working on the different levels of practice from direct practice to policy practice in order to make a change.

In two lessons in our course, the historical as well as contemporary emphasis on participatory principles in research, policy and practice in Flanders (the Dutch speaking part of Belgium) is discussed. Since the 1990s, the notion of participation gained prominence in antipoverty policies and social work interventions in the international realm (see Carr, 2007; Cornwall \& Brock, 2005). In parallel with international developments, the implementation of these ideas in Belgium and Flanders is discussed, being captured in the Belgian General Report on Poverty (1994) and the Flemish Poverty Decree (2003). In the course, we situate how the participation paradigm in the Flemish context has crucially informed a definition of poverty being defined as a lack of non-materialistic and cultural capital rather than a lack of material and social resources, which was leading to a dominant belief in a politics of recognition that was splitting apart from social policy and social work actors pursuing a politics of redistribution (Author's own, 2012). We also rely on examples in research, policy and practice to illustrate how the contemporary preoccupation with empowering people in poverty, that is employed to overcome their individual psychology of powerlessness, apathy, and shame (see Depauw \& Driessens, 2016), might serve the reproduction of oppressive, unequal and socially unjust power relationships in society out of the picture. In the two lessons, we invite people with experience in poverty to talk about their work and lives to illustrate the potential transformative 
contributions of participation. During these lectures, we however also explicitly dwell upon the risk of a tyranny of participation that might easily result in instrumental and tokenistic endeavours in social policy and social work (see Cook \& Kothari, 2001).

\section{Methodology}

\section{Situating the course and strategies of data collection}

During the academic year 2017-2018, 26 participants with different backgrounds were enrolled in the post-academic course. They followed the course together with 24 master students in social work and educational sciences. The course started in the beginning of February 2018 and lasted until the end of May, consisting of 10 lessons which covered 40 course hours. Before the first lesson of the course, we organized a meeting to get to know each other, and explored and expressed motivations and frustrations in relation to poverty and social inequality in the current work environments of the students. At that moment, we explained our intent to examine the experiences of the students during the course, which also entails that our research study was qualitative in nature (see Bogdan \& Biklen, 2007).

In that vein, two qualitative and complementary research methods were combined. We invited them to write two individual reflection papers that captured their personal experiences, critical incidents and reflections, one in the beginning of the course and one after the course was finished. The individual papers were combined with two focus group conversations to deepen the knowledge and insights and to enable a collective discussion and reflection between the students and 12 teachers. After the first focus group, we invited a guest speaker to teach the group about the core principles of the poverty-aware paradigm (PAP) in social work.

The study has been approved by the institutional review board of our University on the $\mathbf{2 9}^{\text {th }}$ of January 2018. 23 of the students agreed and were available to take part in this pedagogical 
experiment, and signed the informed consent that was offered at the start of the first focus group. We constructed questions and research topics for the students that were used for the development of the individual reflection papers as well as in the focus groups, that made the conceptual framework of PAP operational, including topics such as personal motivations and frustrations, individual knowledge, experiences and reflections in relation to social work organizational cultures and strategies, assumptions and viewpoints about poverty, social inequality, and anti-poverty strategies.

This research endeavor resulted in two papers of each of the participants, and three focus groups to discuss this (after phase 1 and phase 2). The focus groups took place on the $20^{\text {th }}$ of March and the $14^{\text {th }}$ of May 2018, and each lasted two hours. On the $14^{\text {th }}$ of May, we organized two separate focus groups to enable rich discussions with a reasonable and feasible number of participants. The focus groups were fully transcribed (see Howitt, 2010).

\section{Strategies of data analysis}

We analyzed the data (the individual reflection papers and transcriptions of the focus group conversations) through a qualitative content analysis (Patton, 2002). We were using the research insights that informed our educational framework and engaged in 'empirically based feedback loops' (see Hsieh \& Shannon, 2005) to enrich our understanding of how this might contribute to the learning process of our students. We identified five common and interrelated themes throughout the data (Patton, 2002).

\section{Research findings}

\section{From recognizing micro-aggressions to tackling macro-aggressions}

As an interesting finding, our students reveal that micro-aggressions often stem from their own tacit knowledge and that of their colleagues, and often result in so-called subtle but moralizing and offensive interactions with people in poverty. 
The course helped me in grappling with my own tacit and stereotypical ideas ghosting around in my head and practice. (...) To give you an example, I used to judge people who told me that they couldn't pay 50 euro at the end of the month and tell them that this is impossible. That's a very typical middle-class reasoning.

They however also stress the interrelatedness of these relational and interactional dimensions with social, cultural and political ideas, that intrinsically influence their paradigmatic worldview.

As a social worker, we are trained to realize social rights and to detect social injustice. Unfortunately, I am confronted with micro-aggressions in my own work environment on an everyday basis. People in poverty are approached in moralizing, stigmatizing and even punitive ways, they are told they need to work if they want money even if their circumstances or educational background do not provide enough back-up. And in the meanwhile, policy makers prescribe that we can offer them free shampoo and tooth paste as an incentive. How belittling is that...

Here, the students coined the term 'macro-aggressions', which refers to stereotypical thinking that is voiced in their organizational context and in social policy rhetoric. They however argue that it takes a while and a shift in thinking to position themselves in the current time juncture.

The normative value orientation of policy makers and the political settlement has changed; their rhetoric of citizenship and social rights remains the same but the implications are drastic in policy and practice. This is only recently, since the last 
political legislature we can clearly talk about macro-aggressions - politicians who clearly want to dismantle the structures of the welfare state and erode the value orientation. Our Minister of Poverty Affairs, for example, who considers charitable initiatives such as the recycling of food for the poor as the most effective anti-poverty strategy.

\section{Poverty is an instance of social injustice and requires collective indignation}

The course as well as the moments of exchange and discussion seem to offer many of the social professionals the necessary set of ideas and exchange that helps them in breaking their own 'culture of silence', with reference to their alienation of what can be considered as socially just. The fact that they do not consider poverty as an instance of social injustice is however often the result of long-term frustration and feelings of powerlessness in their own organization.

I'm not poverty-blind, but perhaps when times goes by, you become thick-skinned, and you start to reduce issues of poverty and injustice into a kind of unconcerned thinking. This happens due to feelings of powerless, you consider you can't solve the problem of poverty and therefore refuse to face facts. It's like wearing the right glasses in how you approach poverty situations.

The challenge for students entails overcoming their value-neutrality and their positioning in how they can actually make a difference while not being indifferently to the social problem of poverty. This seems to require commitment and even indignation that is not easily downplayed as personal and only emotional impressions or polemical opinions, yet is justified according to the social justice orientation of the welfare state.

We learned how complex it is to create social change and to influence social policies.

We do have a public mandate, and the course provokes me in my commitment for social 
justice. (...)I can underpin my indignation now; rather than being grounded in feelings or impressions my opinion is based on a set of ideas being developed according to a socially just welfare state.

In this process of becoming poverty-aware, both an individual and collective sense of indignation seems to be nothing less than vital and leads to an awareness of how professionals contribute to processes of Othering, and blame people in poverty for their situation. This critical consciousness seems to start with a self-awareness.

The course gave me new energy. I used to blame people in poverty for their problems, I had lost sight of the big picture; poverty is a socially unjust problem. However this required a confrontation with my own assumptions, my own prejudices, my own worldviews.

However, since the culture of silence of social work professionals is often the result of an organizational culture, in which collective reflection and action is missing, poverty-awareness also crucially involves colleagues and a forum for public debate in their organizations and environments.

If you ask me, indignation proves to be a vital aspect in the development of povertyaware strategies. Suddenly I also discovered colleagues who shared this indignation. We were all frontline workers, and this awareness enabled us to join hands in our attempts to make a difference.

\section{Notions of commitment and solidarity are ambiguous}

Although the course explicitly offers abstract, theoretical and practical insights into the difference between charity-based and rights-oriented social work approaches, distinguishing between the features of these normative value orientations in practice proves to be a very complicated challenge for the students. 
I used to believe that the allocation of soup in the railway station for the homeless or a free Christmas party or the donation of second-hand clothes to the poor were very good anti-poverty strategies. However these ideas are currently popular and we get used to perceiving this kind of initiatives, often offered by benevolent volunteers rather than professional social workers, as a progressive commitment. Yet these practices are rooted in $19^{\text {th }}$ century ideas, when the poor were considered as the wretched of the earth.

In that vein, the particular connotation of a 'commitment' towards situations where the rights of people in poverty are violated seems to be very ambiguous. One of the students gives a very clear example.

I experienced a moment of confrontation at the till of the supermarket. A father wanted to buy a bread and nappies, but he couldn't pay the bill and bought only nappies for his son. The person joining that queue was groaning and moaning, and rolling his eyes. Afterwards I felt guilty that I didn't do anything and didn't pay the bread for this father, and decided to give a donation to a local charity organization. Now I realize that it was as if I was redeeming my own sense of guilt, and this trifle donation was only a drop in the ocean. What we need is a commitment to contribute to a socially just welfare state, to mend the holes in the umbrella of our social security system so that all citizens get a decent income.

As one of the students argues, this means that we need to take a stance.

The vital question is how to take a commitment towards people in poverty. (...) Just being engaged in charitable or moralizing ways is not okay. We all too easily make a distinction between the deserving and the undeserving poor.

The historical contextualization of the emergence of rights-based approaches in recent history however seems to make sense, especially the idea of solidarity being translated into social 
security principles that were conceived after the second world war in Europe rings true for students.

In the current time juncture, we often notice that young people have forgotten the idea of social security. And if people still know the basic principles, I have noticed a lack of public support for it. The mantra 'no rights without obligations' always crops up, and is now key to how many people think.

The students also indicate the complexity of asking for a commitment of colleagues, who rely on self-referential and stereotypical arguments about 'the poor' that are not easily challenged.

One of my colleagues said that she didn't want to welcome poor parents in her classroom: "Their iPhone is bigger than mine, and they show no interest in their child since they do not pay their school bills". And this is not the only teacher in our school thinking like this. Those ideas almost implicitly creep into your organizational culture, and they are extremely hard to challenge.

\section{Poverty is an instance of social inequality rather than merely social exclusion}

To develop poverty-aware practices requires that poverty is related to the issue of social inequality rather than merely social exclusion. This is particularly relevant in the Flemish context. As such, a rather exclusive focus on social in- and exclusion leads to a circular reasoning.

How to prevent social exclusion is a tricky question. Policy makers often announce that people in poverty need to make efforts and take responsibility for being included, but they forget that inclusion and exclusion is a mutual process. For powerless people, this requires much more effort; it is unrealistic if you don't reduce social inequality and do not redistribute resources and power. 
The students' shift in thinking about the (re-)production of social inequality is very fruitful, as they learn to see that poverty will remain a very pernicious and stubborn problem if poverty is not perceived as a social problem for all citizens in a society rather than as an individual problem of the poor.

Despite all efforts, there will be no substantial change if the gap between the rich and the poor is not reduced and if there is no structural redistribution of wealth and power. To expect efforts only from people in poverty is unfair, since they are at the bottom of the social scale and their socio-economic resources are decisive for their potential mobility out of poverty.

The students also mention their experiences with a particular strategy being applied in Flanders (the Dutch speaking part of Belgium) to tackle processes of social exclusion; if participation is perceived as a way to redistribute power and tackle social inequality too, it is a complex but necessary venture.

If participation serves as an eye-opener for everyone in our society, it can enable us to see that poverty reduction is a common concern that matters to all of us. This requires dialogue and solidarity which involves stakeholders across all the different positions on the social scale.

\section{From being heroic agents to social change 'from within'}

Many students start the course with feelings of powerlessness and disappointment about their own organizational context and colleagues, and about wider societal beliefs. The rationale to follow the course often stems from such experiences. 
During the last months, I was personally fighting on the barricades to be heard and bring social change. But it didn't work out at all and I was totally exhausted, ending up in an acute burn out and sick leave. I even stopped believing in my job, in existential ways. Now the course gave me new energy, I have a different mindset in my activism.

The students often experienced that their indignation about problems and situations of poverty is counterproductive, since their colleagues do not necessarily share the same convictions and often blame them for being naïve.

In the discussions at work, I often experienced a kind of battle to convince my colleagues. However, my fights did not influence their ideas, and they told me I'm way too nä̈ve or too radical. Eventually I think I was just banging my head against a brick wall. But perhaps I was just too offensive in voicing my concerns, which caused defensive responses. As Yuval Saar-Heiman [one of the teachers] argued to aptly "there is a difference between judging and being critical". However, it makes me doubt what might be a good strategy to persuade others?

The discussions and exchange with fellow students and teachers during the course clearly helped the students in embracing the complexity of developing a poverty-aware viewpoint; they realize that they cannot simply solve poverty and therefore it requires more than only loud shouting and accusing others for not being committed.

I think we need a firmly grounded frame of reference to develop and underpin good arguments, consisting of facts and figures and a set of historical as well as contemporary sound and analytical ideas. Otherwise our arguments might be polemical or intuitive in nature. Now I can motivate a diverse set of arguments.

During the course, different teachers used metaphors to challenge the students to take a stance, such as being a strategic chess player or acting like a happy Sisyphus (Authors). It is remarkable 
how these metaphors enable the students to use their social imagination and think about strategies that might bring social change 'from within', during which their individual efforts also bring collective persuasion due to continuous moments of critical reflection and exchange. They learn to position themselves in more nuanced and pertinent ways as applied social policy makers, who embrace the complexity and irony of their work.

The metaphor of Sisyphus was extremely fruitful, it has strongly influenced my way of taking a stance in public debates. We need both remedial and structural approaches. I first thought it was a trivial difference, but these ideas help me to move beyond being indifferent, or being way too relativistic and making my practice meaningful. We cannot solve the problem of poverty, but we need to deal with this irony while exercising strategic influence. 
Lessons learnt for the development of a poverty-aware pedagogy

As the findings of our study illustrate, the post-academic course on 'Poverty and Participation' led students to critically evaluate their tacit knowledge regarding (people living in) poverty. Our study provides an interesting example of how students, who are already involved in social work practice, critically reconsidered both their theoretical ideas and practical strategies in dealing with poverty. The benefit yet equally well the pitfall of the course is the post-academic level, which entails that the participants are already involved in, and have experienced how to shape social work practice. This creates the potential that the course might enable them to take some critical distance of the practices in which they are enmeshed and to reorient themselves, yet also the risk that they consider assumptions that have been institutionalized as self-evident. The study consequently also has methodological limitations, since it investigates the viewpoints of students being involved in a post-academic course rather than the perspectives of bachelor and master students in social work. For bachelor and master students who have little practical experience, it might be difficult to learn how to tackle and deal with the social problem of poverty due to a lack of experience.

Our findings however indicate that the intensive and collective series of lessons and discussions often lead to an increased reflexivity in the work environment of the students, and to attempts to affect and change their own ways of working rather than only their own ways of thinking. Our findings show that poverty-aware pedagogy and education is not solely an intellectual endeavor but also a normative and transformational one. Aside from enabling students to critically deconstruct personal and public ideas on poverty and poverty alleviation, the course proved to stimulate the participants to 'take a stance' and position themselves in relation to their environment and the wider historical and socio-political 
context. Poverty-aware pedagogies are thus both 'deconstructive' and 'reconstructive', and should be 'productive' or 'transformational' in nature (Morley, 2008). In other words, social work educators should invite students to formulate not only alternative conceptions of social justice, solidarity and commitment, but also to reinvigorate the social justice aspirations of social work practices at the individual, organizational and societal level.

As a critical recommendation for social work educators, moreover teaching students and practitioners about poverty-aware social work requires pedagogies of critical reflection in a diversity of fields of social work practice but also preferably collective and longlasting supervision. Our research shows that we should be cautious to reduce critically reflexive/poverty-aware social work to an individual activity or responsibility. Since poverty remains an intractable social problem, students aptly noted that poverty-aware social work demands a critical commitment to combat social injustices and inequalities at the organizational and societal/social policy level as well. A poverty-aware professional attitude cannot be restricted to self-reflection on personal values or assumptions, and requires a critical analysis of the political-economic and social policy contexts that shape the social work profession and discipline. In that vein, both a relativistic value-neutrality and oppositional activism are considered undesirable; since social work can only offer a poor answer to social problems such as poverty yet "as we do not have any better answers (...) we must have this cake and eat it" (Author's own, 2013). Collective critical reflection but also continuous learning and supervision might challenge powerlessness of social workers, and open up avenues to collectively challenge and change socially unjust social policy rhetoric and practice (Gould \& Baldwin, 2006). Indeed, throughout the course, several students rediscovered a sense of agency to re-imagine possible ways of resistance and actual ways to bring social change 'from within' (Fook \& Askeland, 2006; Morley, 2008). Nevertheless, some students were uncertain about how to translate new insights gained in the course to 
everyday practice or how to persuade colleagues to join their critical and poverty-aware work. The limitations of our course might be that it mainly introduced students to new grammars and analytical frameworks that allow them to deal with instances of poverty in critical and reflexive ways, that neither ignore the social and historical forces that shape social work and its interventions towards (people in) poverty. However the course might not enable and support the students as practitioners enough to deal with the ambiguous, complex, and intractable nature of working with (people in) poverty in the long run.

\section{References}

Author's own (2009).

Author's own (2012).

Author's own (2012).

Author's own (2016).

Author's own (2017).

Author's own (2018).

Bogdan, R. C., \& Biklen, S. K. (2007) Qualitative research for education: An introduction to theory and methods ( $5^{\text {th }}$ ed.), Boston, Allyn \& Bacon. 
Cantillon, B. (2016) De staat van de welvaartsstaat, Leuven, Acco.

Cantillon, B., \& Van Lancker, W. (2013) Three shortcomings of the social investment perspective, Social Policy and Society, 12 (4), pp. 553-564.

Carr, S. (2007) Participation, power, conflict and change: Theorizing dynamics of service user participation in the social care system of England and Wales, Critical Social Policy, 27(2), pp. 266-276.

Cook, B., \& Kothari, U. (2001) Participation: The new tyranny? New York, Zed Books.

Cornwall, A., \& Brock, K. (2005) What do buzzwords do for development policy? A critical look at participation, empowerment and poverty reduction, Third World Quarterly, 26(7), pp. 1043-1060.

Davis, A., \& Wainwright, S. (2005) Combating poverty and social exclusion: Implications for social work education, Social Work Education, 24(3), pp. 259-273.

Dean, H. (2015). Social rights and human welfare. London: Routledge.

Depauw, J., \& Driessens, K. (2016) Taking the measure : a participatory approach to measuring and monitoring psychological empowerment in social work practices, European Journal of Social Work, 20(4), pp. 522-535 
Fook, J., \& Askeland, G. (2007) Challenges of critical reflection, nothing ventured, nothing gained, Social Work Education, 26(5), pp. 520-533.

Freire, P. (1970) Pedagogy of the oppressed, New York, Continuum.

Garrett, P. M. (2002) Social work and the just society: Diversity, difference and the sequestration of poverty, Journal of Social Work, 2(2), pp. 187-210.

Garrett, P. M. (2018) Welfare words: Critical social work and social policy, London, Sage.

Gould, N. \& Baldwin, M. (2006) Social Work, Critical Reflection and the Learning Organisation, England, Ashgate.

Howitt, D. (2010) Introduction to qualitative methods in psychology, Harlow, Prentice Hall.

Hsieh, H. F., \& Shannon, S. E. (2005) Three approaches to qualitative content analysis, Qualitative Health Research, 15(9), pp. 1277-1288.

IFSW (2012). Poverty eradication and the role for social workers. Retrieved from http://ifsw.org/policies/povertyeradication-and-the-role-for-social-workers.

IFSW (2014). Global definition of social work. Retrieved from http://ifsw.org/getinvolved/global-definition-of-social-work. 
Larson, G, \& Allen, H. (2006) Conscientization: the experience of Canadian social work students in Mexico, International Social Work 49(4), pp. 507-518.

Lister, R. (2004) Poverty, Cambridge, Polity Press.

Lorenz, W. (2008) Paradigms and politics: Understanding methods paradigms in an historical context: The case of social pedagogy, British Journal of Social Work, 38(4), pp. 625-644.

Lorenz, W. (2016) Rediscovering the social question, European Journal of Social Work, 19(1), pp. 4-17.

Marston, G., \& McDonald, C. (2012) Getting beyond heroic agency in conceptualizing social practitioners as policy actors in the twenty-first century, British Journal of Social Work 42(6), pp. $1-17$.

Morley, C. (2008) Teaching critical practice: Resisting structural domination through critical reflection, Social Work Education, 27(4), pp. 407-421.

Morvaridi, B. (2016) New philanthropy and social justice: Debating the conceptual and policy discourse, Bristol, Policy Press.

Patton, M. Q. (2002) Qualitative research and evaluation methods, California, Sage Publications, Thousand Oaks.

Ridge, T., \& Wright, S. (2008) Understanding inequality, poverty, and wealth: Policies and prospects, Bristol, Policy Press. 
Rigney, D. (2010) The Matthew effect: How advantage begets further advantage, Columbia University Press.

Van Regenmortel, T. (2007) Empowerment en vraagsturing in de zorg: Onlosmakelijk verbonden? Tijdschrift voor Welzijnswerk, 31(288), pp. 6-14.

Veit-Wilson, J. (2000) States of welfare: A conceptual challenge, Social Policy \& Administration, 34(1), pp. 1-25.

Villadsen, K. (2007) The emergence of 'Neo-Philanthropy': A new discursive space in welfare policy? Acta Sociologica, 50(3), pp. 309-323.

Vranken, J. (2007) Armoede is niet gezond. In J. Vranken, G. Campaert, K. De Boyser, \& D. Dierckx (Eds.), Armoede en sociale uitsluiting: Jaarboek 2007 (pp. 25-37). Antwerpen: Acco.

Weiss-Gal, I., \& Gal, J. (2014). Social workers as policy actors, Journal of Social Policy, 43(1), pp. 19-36.

Wilkinson, R., \& Pickett, K. (2009) The spirit level: Why more equal societies almost always do better, London, Allen Lane. 